\title{
Sounding the Truth in Academic Writing
}

\author{
Teguh Rokhmani', Bedjo Sujanto ${ }^{2}$ and Muchlis R Luddin ${ }^{3}$ \\ \{teguhrokhmani@yahoo.com¹, bejosujanto@unj.ac.id ${ }^{2}$, rantoni-luddin@unj.ac.id ${ }^{3}$ \} \\ ${ }^{1}$ Post Graduate Program Student of Universitas Negeri Jakarta,Jl. Rawamangun Muka, \\ RT.11/RW.14, Rawamangun, Pulo Gadung, Kota Jakarta Timur, Daerah Khusus Ibukota \\ Jakarta 13220, Indonesia \\ ${ }^{2}$ STIS Kebumen, J1. Raya Kutoarjo Km.12 Mekarsari Kutowinangun Kebumen Jawa Tengah \\ 54393, Indonesia \\ ${ }^{3}$ Post Graduate Program of Universitas Negeri Jakarta, Jl. Rawamangun Muka, \\ RT.11/RW.14, Rawamangun, Pulo Gadung, Kota Jakarta Timur, Daerah Khusus Ibukota \\ Jakarta 13220, Indonesia
}

\begin{abstract}
The article purposes to describe some problems of ethical issues of writing for academic paper as part of academic responsibility. The dissemination of academicswriting do through international journals. There are some several reasons, such as enhancing personal and university level, widening networking, implementing a better academic atmosphere, and academic work. However, Indonesia academics are still have some problems in academic work especially writing international journal, such as lack of ability in writing and low research. This case study was conducted qualitatively in 2017 with data collection method through in-depth interviews, observation, and document studies. The result shows that hence, the article discusses the unethical practice in academic writing as misconduct, fabrication, falsification and plagiarism or handling the prevention. In sumthat paper involves two aspect discourses: the unethical of academic writing and how to avoid this worse work., therefore, quality of the journal reflects the quality of the writing.
\end{abstract}

Keywords: ethical issues, academic writing, international journal, research misconduct

\section{Introduction}

Research integrity is the basic of public's trust in the academic research [1]. In institutions of higher education academic integrity receives a great deal of attention. Universities and colleges attend specific honor codes or have administrative units to resolve dishonesty allegations and promote good behaviors. To ensure their degrees' value and preserve respect for their institutions, students, faculty, and staff have stakes in maintaining high levels of academic integrity [2]. Truthful, fair play and integrity is the basis of the academic institution generating. This belief is broken when academic community take in academic misconduct, either deliberately or inadvertently. Although people are highly ethical and know how to differentiate between right and wrong. They never plagiarize, falsify or fabricate data. Understanding research ethics has an important role in producing academic writing in regarding research integrity. In addition, most of colleagues are highly ethical and that there are no ethics problems in research.

When and if one talk about "ethics," one imagines between right and wrong, good and bad, codes of conduct, guidelines for attitudes and behaviors, rules for dealing with others or for knowing the difference. As moral guidance, ethical guidelines function prior to action., 
ethics are often considered prior to the conduct of a study as a part of research design [3]. Ethics is said as the branch of philosophy which relates to the vibrant of conclusion making referring whether is right and wrong. Scientific research activity, as all human work, is directed by personal, society and communal norm. Involvement of research ethics requirements is required on daily work, the security of subjects value and research publication.

Ethic increase the aim of research which consists of the dissemination of knowledge, telling or reporting the truth and the need to counteract errors finally. Many steps that are urgent in research start with writing research proposal and acceptance leading to the proper research study. A researcher must choose suitable methodology to engage, relevant ways of data collection, serve the research findings and interpret them base on guiding to presentation of evidence in a logical series. Then the data is analyzed and reported well in form of an article, book, thesis or project report. Observation of a researcher in appropriate values at all these stages while conducting research is important. It could produce into research misconduct if this is not observed,. Ethical issues related to research focuses on those related to the research subjects, research process and the research itself.

In science, misconduct in research has a long history [4]. In the USA, these topics have been in the public issues since a number cases of fraud were opened at honored US research institutions during the 1970s and 1980s [5]. Based on Garfield's [6] historiography, total about 1000 publications have discussed the topics of "Misconduct in Science" since the 1970s. They were majority published in countries with English as speaking and were mostly letters and material of editorial; articles of research are scarce. There are many grey literature, collected writings and monograph of which Garfield's historiography takes no account.

In a research misconducts are serious cases. These cases have rocked world scientific community in recent years. Misconduct as unethical acting occurs in research, even though there is considerable in vary among various calculates. The misconduct rate estimation to be as low as $0.01 \%$ of researchers per year (based on confirmed cases of misconduct in federally funded research) to as high as $1 \%$ of researchers per year(based on self-reports of misconduct on anonymous surveys) [7].

Crimes in science, i.e. plagiarism, falsification and fabrication, however, most of the crimes related in science are not similar with to murder or rape. The crimes in science compare with the crimes in society, are probably the less serious but ethically significant that are classified by the government as 'deviations. This paper will discuss ethical issues in research, why researchers must be ethically, why does misconduct occur, types of misconduct and how to eliminate it.

\section{Research Misconduct}

There are varies and no valid and standard definition of research misconduct. OSTP definition is that [8]: "Research misconduct is as fabrication, falsification, or plagiarism in proposing, performing, or reviewing research, reporting origin research results". Fanelli [9] arguing in nature, published a statement on research misconduct that misconduct should be redefined as "biased reporting" of all sorts: Misconduct is defined as any omission or the sufficient and necessary of information misrepresentation to evaluate the validity and significance of research, at the level context appropriately in which the research is informed.

There are two central theories about why researchers act misconduct. The first is stressful or imperfect environment and the second is bad apple theory. The phrase that, "one apple spoils the whole bunch" is derived from a 14th century Latin interpret proverb "The rotten apple injures its neighbors"[5] [10]. It is from this proverb that we obtain the "theory of bad 
apple" which stresses the reality that one mold apple could scattered and influence the rest. This is why; a bad apple among a group is synonymous to a bad person. The "theory of bad apple" takes that most researchers some who are corrupt morally are great ethical apart from. Based to the "theory of bad apple", most scientists are ethically high. In accordance with the "stressful" or "imperfect" environment theory, misconduct develops because of tension from institutional variously, barriers, and stimulant drive people to do misconduct. Frequently cited strain to publish or gain contact or grants , career ambitions, to get fame or profit, low supervision of trainees and students, and lack oversight researchers. The stressful environment theory defenders state that system of science's peer review is not perfect and cheat the system is relatively easy to do. Many fraudulent research or erroneous put in the public record without being uncovered for years. To the extent that research environment is an important factor in misconduct, research ethics course could help people to get an understanding better.

Many kinds of research misconducts appear at every step of the research process (recording, generating data, dissemination/publication of scientific work and recording). The most frequently connected with misconduct of research are fabrication and falsification of the data. Data fabrication refers to actually creating fake data sets and results and presenting them as true findings. Related to this is data falsification, altering data to get publishable results, both of which undermine the integrity of the entire review and publication process[11]."Pruning and massaging" can be undertaken through the use of inappropriate methods of data analysis, the (tacit) exclusion of outliers in data analysis [12]. As the manipulation of graphics is a relatively frequent problem in journal manuscripts, some editors already employ specialists to examine graphics for unpermitted (or still permitted) manipulation [13]. Fabrication consists of creating, inventing or faking data or results which are then reported or recorded while, falsification or fraud is the manipulation of materials, equipment, processes, by changing results or erasing data or findings so that the research does not seem to have been well represented or recorded [14].

The other area typically related with research misconduct is plagiarism: passing off intellectual property of someone else's (ideas or information) as one's own achievement without giving the proper source (e.g., in research papers) [13]. Plagiarism is derived from the Latin word plagium, meaning stealing a slave or child [15] Therefore, plagiarism is the action of imitating text, language or idea of someone else and publish it as it is his/her own work. From the definitions above it is very clear that the authors should avoid their own manuscripts from plagiarism because it is against the law, and [16].

In the internet era, this kind of misconduct is acquiring great significance: "There is now a great amount of information available via the Internet; text is very easy to duplicate and paste, and ideas can be collected from a multiple of sources" [13]. Someone is considered to be plagiarism while copy 10 words in a text, others need at least 30 . Plagiarism raises some problems for the system of reward operating it. The most valuable capital to sciences are discoveries and invention. According to Cameron et al., [17] the reality that the majority of the scientist publish their work in English has crucial implication for training about practice of publication standard, especially with regard to plagiarism.

\subsection{Factors Raising Plagiarism}

The authors who have plagiarism in their paper divide into two types. Firstly is the direct plagiarizing that the authors plagiarize by copying another authors' text exactly as it is, and prevailing as his/her own work. It is known as copy-pasting in applying word process. Secondly, type is about authors who plagiarize unconsciously. Many factors which may raise these problems. Some of these factors are as follows [14]: 


\subsubsection{Uncited Thought\& Concepts}

Many a rticles have to read by Scholars are used to enhance other methodologies to contribute more in science. They should evade the same words use and the text language structural originally

\subsubsection{Join Writers}

There might be many writers involved in many papers. Yet, not every single writer is conscious whether the others have been fair and ethical in their manuscripts or not. In a join work, what authors write is responsibility for what he/she composes, but all writers are responsible for the whole published material while it is published.

\subsubsection{Similarity by Chance}

Another factor is when the writer text of has been nearly similar to another writer's by accident. When a sentence or an idea is as common as everyone uses in his/her own text, it is probably that a sentence or a concept would be known as plagiarism in plagiarism finding systems.

\subsubsection{Fixed Definitions}

At almost all sciences, there is fixed definition which author writes and cites them, at certain sciences modification would make the meaning move or swift.

\subsubsection{Self-Plagiarism (Similarity)}

Researchers are sometime publish their works more than one from research. Although they are different, there are many similarities in different sections of the articles. The following three cases are plagiarism in these papers:

a. Redundancy and Duplication: Dual publication is another name. It is publication of a article of research in more than one journal. Dual publication is not usually regarded as plagiarism. Dual publication is accepted and ethical in two cases:

- bstracts and summaries which have been publish and presented and in a proceedings of conference can be published in a journal with some extension on the original paper. The extension should be $30 \%$ minimally.

- An article can be republished in different language. However in the second publication, should mention and address the original (first article).

\section{b. Salami Slicing}

The authors produce many articles on different part of the research such as reviewing of literature and methodology. They probably separate the results (fragmentation of the data) in order to raise research papers differently. In all these papers, the primary such as the Introduction and Statements of Problems are not different to each other. Hence, it is difficult to write the same concepts in different words. Some writers only copy the text from published papers they own before. There is data augmentation another issue besides data fragmentation. Data augmentation is the publication of the research which have been published previously, and subsequently, the writers would collect new data to enhance the result and the research contribution. The readers might easily disoriented after both results joined together and get published it (malpractice). 


\section{c. Copyright Infringement}

The act of copying a text from the author's previous published manuscripts is another case of plagiarism. It was published under the copyright of a publisher although the authors have written the original text. In accordance with the rules and regulations of copyright, doing a copy of the published article in whole section or a part is regarded as plagiarism (or self-plagiarism). The problem of misconduct as plagiarism and its causes have been discussed. However the main problem is to answer the question on "How to prevent the plagiarism?"

\subsection{Preventing Plagiarism}

The authors with plagiarism consist of two types. Firstly, group of authors who are conscious of plagiarism and what they act. Solution for this type is giving them adequate education on effect of ethical and unethical article. Secondly, type consists of the authors who plagiarize unconsciously without any motive to do so. Thus, there are two main methods to hide plagiarism by these two types of authors: 1) Ethical methods, 2) Unethical methods. Ethical methods speak about how to replace the text properly so to reduce and to prevent the actually amount of the plagiarism. Unethical methods set the solutions to lowering the plagiarism by avoiding the software of plagiarism detection.

\subsubsection{Ethical methods}

Ethical methods centralize on the structure and text words to replace them properly and to reduce the percentage of similarity as much as possible. The use of this techniques should consider correctly of citing the references articles.

a. Thesaurus/Dictionary Help

A statement with the copied words is a plagiarized sentence. Changing the words with synonyms and antonyms can assist the authors to reduce the possibility and numerous of similarity in the context. Dictionaries and thesauruses are good things for this aim. These tools not only eliminate the plagiarism rate, but also it makes texts fluent and beautifies by substituting the words repetition in a paragraph. Although it is not ethical technically because substituting the words do not change the structures of sentences. But It is ethical having the another approach to prevent

b. Reading Extension

The readers will get the concept of context set in his mind if they reading from many resources. But, many times reading a text would have the words of context set in mind but not the concept. To memorize a text people usually do this (reading a single text many times).

c. Machine Translators Use

It is difficult to compose a sentence has a same meaning in some structures (paraphrase); if they cannot get any to solve rather than to copy the original location from. It is not usually probable, or it is spending time to find people to paraphrase. Translators machine use is a very easy although it is not the best solution.

d. Indirectly Writing after Reading

Generally people write precisely what they have just read. Writing directly after reading has the advantage of being appropriate and not loosing any important section, but it also enhance the opportunity of connecting with plagiarism in the text.

e. Proofread as Many as Possible 
Authors submitted their works for publication just having completed with writing. Having as many as possible the paper proofread do some replacement and correction in the language structure of the article although they might be very well in composition or convinced in the science, but. These transformation would reduce the similarity and plagiarism .The writers should be understand of three issues. The first, they ask people with the same discipline of research to proofread the text. So, they could modify the context as the same meaning. People from different research field can make amphibologies and opacities in the context. Secondly, Authors spread the paper to many readers can enhance the piracy research risk. Other colleagues may publish the article before the main author publishes the manuscript. Therefore, the authors should get the suitable people who are credible and bona fide. Thirdly, reviewing the paper after the proof readings every time. Although the writers believe the colleagues competence who proofread the paper. It is better they recheck to see some mistakes or twist the meanings when they edit the article.

f. Context of Imaginative and Realistic

The new ides are born from imagination. Researchers use imagination and carry them to be factual, appreciate them by composing, feeding, increasing, reviewing and finally publishing them A solution (methodology) plays one of the most important roles for the whole journey of the research. Imagination potential opens a new way to solve the problem . Imagination writing is often and primarily plagiarism-free, because they are basically the authors' assets.

g. Self-Reading Periodically

When the authors have just written, they may only find the grammatical mistakes or missing word in the text. However if the writers reread the text a some days later, they can find more mistakes such as dim sections, or even finding more new sentences written in order to increase the paper. Periodically self-reading the paper can correct the mistakes, enhance and the writing quality of.

h. Quoting

There are some cases that the authors get themselves unavoidable to write the fixed words as the text originally. For instance it is a familiar to say, an abbreviation in scientific or a popular expression. In these occasions, the solution is using quotation. Quoting words from others is usually neglected and not being regarded as plagiarism. Placing the text into two quotation marks and referencing the source at the end of the statement is this technique. For instance, "A person who never made a mistake never tried anything new"-Albert Einstein.

\subsubsection{Unethical methods}

Unethical methods is the techniques to reduce the plagiarism without any attempt to replace the original text. These techniques purpose to bypass plagiarism finding algorithms and to gain a reasonable result of plagiarism on a highly plagiarized context [18]. These methods are discussed and elaborated to inform readers to prevent and to be aware of these methods. It is to make sure that these techniques do not been practiced to the create articles to be published.

a. Replacement of Space

There is a simple space between words to differentiate with another. But in fact, spaces set the words. Space in a text explains that there is hundreds of characters even with one word. This method is used to dismiss the spaces of a text for software of 
plagiarism finding, but contrary, the humans are able to detect it. The characters will not readable in area of numerous text when the spaces would be substituted with some Chinese characters or dots or then colored to white. But in the detection software of plagiarism, just one word as it processes the plain text and eliminates the rich-text's styles would be considered. The following example is themain text and its space-replaced version [19] Original Text:

"it was necessary to match text encoding with a font using the same encoding system. Failure to do this produced unreadable gibberish whose specific appearance varied depending on the exact combination of text encoding and font encoding."

Chinese character replaces the spaces in the second text

画it 画was 画necessary 画to 画match 画text 画encoding 画with 画 $a$ 画font 画 $u s i n g$ 画the 画same 画encoding 画system.画Failure 画to 画do 画this 画produced 画unreadable 画gibberish画whose 画specific 画appearance 画varied 画depending 画on 画the 画exact 画combination 画of 画text画encoding 画and 画font 画encoding.

37 words in the textabove is considered as a one word for software of anti-plagiarism with the there is no space in the whole text as same numberof characters.

b. Translation Automatically

A translation of a text from one language into another by using computer systems is System Translation (SysTran) (Google, 2011; SysTranSoft.com, 2011). Many users use these systems and these systems have been improving every time. Al though these systems cannot precisely translate the text as a humans do, their speed are very and their products are credible. It is a double-sided blade using SysTran for an academic paper, which has ethical and unethical norms. There are many of research studies which available in other languages, and they have not been transformed into English. It is viewed as an unethical way using SysTran to translate the research and publish as his/her own manuscript. Because they has been claimed the works which is not the author's original articles.

\section{c. Replacement of Synonyms}

There are dictionaries or thesaurus to support synonyms or antonyms for the words in word processors. The author can change the words with similar in a paragraph with their synonyms. Even though these features assist, plagiarism from a copied text can be decreased. The systems of plagiarism detection always fail to find them when several words in a copied text replaced with their synonyms. Although the end texts have been different, the authentic structure of the context is still similar, and it is regarded as an unethical way to decrease the plagiarism.

\section{d. Text Picture}

Systems of plagiarism detection process just the text of an article, and they simply neglected the pictures. They would be jump because the system cannot detect the text in the pictures of an article [17]. It is not only hard for the system to detect, but also having a text picture can be recognized manually for humans when the authors enter the text in an image For instance, Word document with text picture is very clear to be detected, however in a PDF document, it is difficult to find. 


\section{Method}

This research was conducted using qualitative approach [20]. A case study method was chosen to explore the data. This research was conducted as a part of a qualitative study conducted at Universitas Negeri Jakarta, Indonesia in 2017. The process of data collection [21] was conducted through in-depth interviews with lecturers and students. The deep interview was delivered to obtain data orally. Observation process was conducted to observe and catch the research activity at UNJ Jakarta, Indonesia. There are many activities were recorded and noted and with a camera. To complement the secondary data the documentof studies were carried out related to this research completion. The documents studied in this study were the reports of research, articles of journal, and other literatures which support this research writing. The data analysis was performed by systematic collecting of the data, categorizing the data, reducing the data and concluding the data of research. Validity of the data checked using credibility, transferability, dependability, conformability and triangulation

\section{Result}

The results of this study found that ethics is highly upheld by the UNJ academic community. UNJ even has its own ethical commission. The ethics are escorted, starting from the planning of research in the form of proposals to the implementation of research and dissemination of research results. To prevent bad behavior, UNJ applies a strict antiplagiarism system. This is evidenced by the use of the latest software, turn it in, to detect potential fraud in the form of plagiarism of scientific works.

It was suitable with participant 9 statement that there are two ways to prevent plagiarism, firstly they make guidance which organized by Vice Rector I and secondly using Turn it in software. Meanwhile the participant 2 said that plagiarism prevention as consequences of ethical research. She stated," Now it is about plagiarism issuance, Vice Rector I have given trainings how to avoid plagiarism by some training to check plagiarism, with turn it in training."

This finding is in line with a number of other studies that emphasize the importance of ethical aspects in research, such as Markham [3] who emphasizes that in reflexive research on ICT, ethical aspects cannot be excluded. Likewise with the aspect of plagiarism, the precautionary measure is in line with what was stated by Harliansyah [22] that in addition to the use of software, the prevention of plagiarism can be in the form of integration of other macro programs, for example by involving various parties in universities, faculties and libraries.

\section{Discussion}

Another thing related to the delivery of truth is the sincere and continuous effort of the UNJ academics to avoid the practice of plagiarism in publications. This effort is in line with Eret and Gokmenoglu's research [23] stating that academics do understand plagiarism, and they try hard to avoid it. Furthermore, Eret and Gokmenoglu revealed the factors that made academics do plagiarism, including limited use of foreign languages, time, lack of understanding of plagiarism, overcrowding of academic activities, lack of academic skills, and others. This was overcome by UNJ by providing training on plagiarism.

It was stated by participants 1 who said that there was three committee. One of them was ethics committee besides academic and work committee at university senate. This committee was breakdown into book guidance of ethics. In addition participants 11 confirmed that now 
UNJ has applied anti plagiarism system, turnitin,. So if the works which detected with plagiarism will be rejected their research result. Even it was start from undergraduate program at UNJ.

The results of this study at least reinforce the views of Larkham and Manns [24] who argue that plagiarism is one aspect that must be cared for by higher education institutions. As Sauders revealed in Larkham, plagiarism can be seen as an issue of trust. Academics are the gatekeepers for the profession, where the profession does not allow fraud to be carried out by students, both at the diploma and postgraduate level. Because, students who cheat will produce practitioners who are also cheating.

\section{Conclusion}

Academic integrity is very important to nurture the higher education value. The degradation of integrity will reduce original value of scientist and academic work. In addition, these academic integrity values should be implemented to society and the workplace. Higher education institutions such as college and university should give more attention on academic integrity by providing special codes or own administrative department to support good conduct and prevent illegal statement. The higher education institution should help decrease the misconduct by increasing the researcher's knowledge of ethics and by improving the sense of researchers. The researchers should be helped to deal with ethical problems. They should be introduced with several prominent principles, concepts, methods and tools to overcome these problems.

Acknowledgements. We would like to thank the Ministry of Religious Affairs (MoRA) of Indonesia, Ministry of Education and Cultural (MoEC) of Indonesia, Endowment Fund for Education (EFE), who helped us materially and morally so that this article could be completed. And all that we cannot mention here, who helped us in any form. Thank you very much for your contribution.

\section{References}

[1] M. Paulsen, Ed., Higher Education: Handbook of Theory and Research, vol. XXVIII. 2005.

[2] R. Mchaney, T. P. Cronan, and D. E. Douglas, "Academic integrity: Information Systems education perspective," J. Inf. Syst. Educ., vol. 27, no. 3, pp. 153-159, 2016.

[3] A. Markham, "Ethic as method, method as ethic: A case for reflexivity in qualitative ICT research," J. Infor. Ethics, vol. 15, no. 2, pp. 37-54, 2006.

[4] G. Charless, "Scientific Misconduct," Annu. Rev. Psychol. i, vol. 67, pp. 693-711, 2016.

[5] D. L. McCabe, L. K. Trevino, and K. D. Butterfield, "Cheating in academic institutions: A decade of research," Ethics Behav., vol. 11, no. 3, pp. 219-232, 2001.

[6] E. Garfield, "Historiographic mapping of knowledge domains literature," J. Inf. Sci., vol. 30, no. 2, pp. 119-145, 2004.

[7] J. Resnik and B. David, "What is Ethics in Research \& Why is it Important?," Natl. Inst. Environ. Heal. Sci., no. January 2007, pp. 1-10, 2015.

[8] S. L. (USC) Rose, D. Ph, J. (USC) Hagemann, M. (USC) Aburto, and D. (USC) Shahnazarian, "Avoiding being penalized: research misconduct," Off. Prot. Res. Subj., pp. 4-17, 2009.

[9] D. Fanelli, "Redefine misconduct as distorted reporting," Nature, vol. 494, no. 7436, 
pp. 149-149, 2013.

[10] Naseem Shah, "Ethical issues in biomedical research and publication," J. Conserv. Dent., vol. 14, no. 3, pp. 1-8, 2011.

[11] N. C. Herndon, "Research fraud and the publish por Perish world of academia," $J$. Mark. Channels, vol. 23, no. 3, pp. 91-96, 2016.

[12] P. O. of S. and Technology, "Peer review," no. 182. [5] Parliamentary Office of Science and Technology, London, pp. 1-4, 2002.

[13] I. Hames, Peer review and manuscript management in scientific journals. Oxford: Blackwell Publishin, 2007.

[14] Sunmeet Kour, "Ethical and legal issues in educational research," Indian J. Appl. Res., vol. 4, no. 6, pp. 133-135, 2014.

[15] Stuart P Green, "Plagiarism, norms, and the limits of theft law: Some observations on the use of criminal sanctions in enforcing intellectual property rights," Hast. Law J., vol. 52, pp. 167-242, 2002.

[16] K. Bakhtiyari et al., "Ethical and unethical methods of plagiarism prevention in academic writing," Int. Educ. Stud., vol. 7, no. 7, pp. 52-62, 2014.

[17] C. Cameron, H. Zhao, and M. K. McHugh, "Perspective: Publication ethics and the emerging scientific workforce: Understanding 'plagiarism' in a global context," Acad. Med., vol. 87, no. 1, pp. 51-54, 2012.

[18] L. Gillam, J. Marinuzzi, and P. Ioannou, "TurnItOff - Defeating Plagiarism Detection Systems," Proc. 11th High. Educ. Acad. Annu. Conf., 2011.

[19] A. Patel, K. Bakhtiyari, and M. Taghavi, "Evaluation of cheating detection methods in academic writings," Libr. Hi Tech, vol. 29, no. 4, pp. 623-640, 2011.

[20] Creswel. John W, Research Design, 4th ed. California, 2014.

[21] D. Ary, J. L. Cheser, S. C. K., and R. Asghar, Introduction to research in education, 8th ed. Wadsworth: Cengage Learning, 2010.

[22] F. Harliansyah, "Plagiarism dalam karya atau Publikasi Ilmiah dan langkah Strategis Pencegahannya," LIBRIA, vol. 9, no. 1, pp. 103-114, 2017.

[23] E. Eret and T. Gokmenoglu, "Plagiarism in higher education: A case study with prospective academicians," Procedia - Soc. Behav. Sci., vol. 2, no. 2, pp. 3303-3307, 2010.

[24] P. J. Larkham and S. Manns, "Plagiarism and its Treatment in Higher Education," $J$. Furth. High. Educ., vol. 26, no. 4, pp. 339-349, Nov. 2002. 